\title{
Assessment of Serum Levels of Interleukin-23 in Patients with
}

\section{Alopecia Areata}

\author{
Abdelraheem Talal ${ }^{(1)}$, Nesreen Mohamed Aboraia ${ }^{(2)}$, Neremeen Aboseif ${ }^{(3)}$. \\ (1) Professor and Chairman of Dermatology, STDs and Andrology Department. \\ (2) Lecturer of Dermatology, STDs and Andrology Department Faculty of Medicine, \\ Fayoum University
}

(3) Department of Dermatology, Faculty of Medicine Fayoum University.

Corresponding author: prof .Talal A. Abd-Elraheem

E-mail address: talasam@yahoo.com

Tel: 01006600360

\begin{abstract}
Alopecia areata is a relatively common skin disease. Scientific theories that explain the causes of this disease vary, but it is often known to be an organic disease of immunogenic origin. Alopecia may be specific or partial through the appearance of one or more spot free of hair and may be complete through the absence of hair For the entire scalp. The actual causes are not known, but the closest perception of the majority of scientists indicates a dysfunction of autoimmunity. The aim of this study was to evaluate the levels of IAA expression in blood in alopecia patients compared to normal individuals in an attempt to assess the role of IAA.
\end{abstract}

KEY WORDS: Alopecia, IL-23, pathogenesis

\section{INTRODUCTION}

Alopecia areata (AA) is a disease that causes marked cosmetic deformity and psychological morbidity, leading to hair loss on the scalp, face and body. Although, the pathogenesis of AA is poorly understood, evidence which suggests that $\mathrm{T}$ cells and cytokines play an important role is accumulating [1].

Interleukin-23 (IL-23) is a heterodimeric cytokine produced predominantly by activated antigen presenting cells, such as macrophages and dendritic cells. The cytokine is composed of a unique p19 subunit and a p40 subunit that is shared with the Th1 signature cytokine, IL12 [1].

Cytokines produced by Th17 cells are highly pro-inflammatory and are now associated with various autoimmune diseases, such as psoriasis, rheumatoid arthritis and AA [2]. The IL-23/IL-17 axis, therefore, is one of the main cytokine axes driving the pathogenesis of various autoimmune diseases. Sera IL-23 and the number of Th17 cells were elevated in various autoimmune diseases patients compared to control subjects [3]. 


\section{PATIENTS AND METHODS}

This study was carried out in the dermatology department of Fayoum University Hospital. Lab work was performed at the Clinical Pathology Department of Fayoum University Hospital cross sectional study.

Our study included 80 individuals divided into two groups:

Group 1: This group included 40 patients of AA without atopic background.

Group 2: $\quad$ This group included 40 apparently healthy volunteers as controls which are age and sex matched with the patient group.

\section{Exclusion criteria:}

Patients were excluded from the study if there was any of the following:
1. Patients receiving systemic drugs (systemic corticosteroids, cyclosporine, or other immunosuppressive therapy) during last six months.

2. Patients who received topical therapy (monoxidl,corticosteroids).

3. Pregnancy or breast feeding women.

\section{Determination of serum IL-23:}

Three $\mathrm{ml}$ of blood was drawn in sterile plain tubes. Blood samples were centrifuged and the serum was frozen at $-20^{\circ} \mathrm{C}$ until assayed. Serum levels of IL-23 were measured using enzyme-linked immunosorbent assay (ELISA) technique (Human IL-23 Quantikine ELISA kit Shanghai Korain Biotech CO. ITD).

\section{Results}

1. Comparison between two groups regarding serum IL-23.

\begin{tabular}{|c|c|c|c|c|c|c|}
\hline & Scalp & Eye brows & $\begin{array}{c}\text { Scalp \& } \\
\text { abdomentleg }\end{array}$ & Bread & $\chi^{\mathbf{2}}$ & P-value \\
\hline No & 35 & 3 & 1 & 1 & 83.6 & $<0.001$ \\
\hline$\%$ & 87.5 & 7.5 & 2.5 & 2.5 & & \\
\hline
\end{tabular}




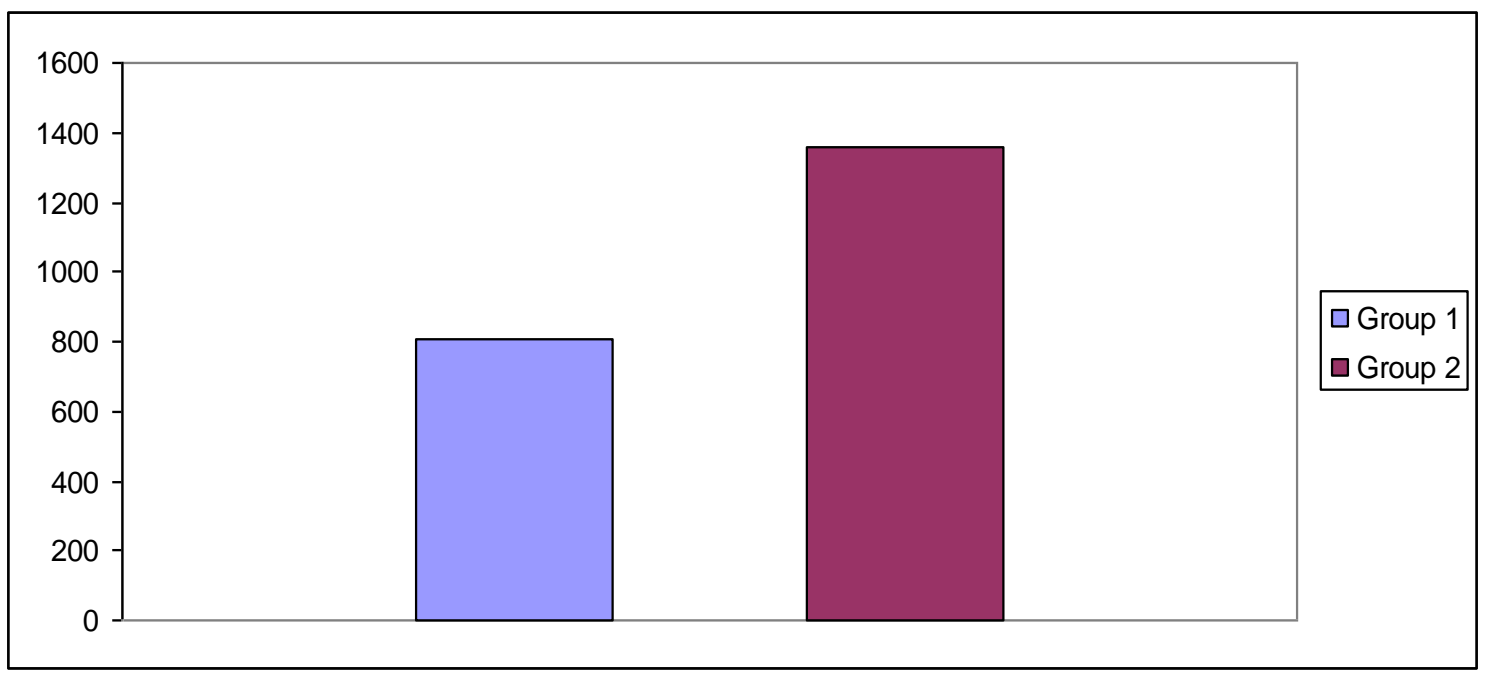

2. Comparison between levels of IL-23 in patients according to disease progression

\begin{tabular}{|c|c|c|c|c|}
\hline & Areata single & Areata multiple & \multirow{2}{*}{ T-test } & P-value \\
& $\mathbf{( 3 1 )}$ & $\mathbf{( 9 )}$ & \\
\hline Mean \pm SD & $962.91 \pm 1042.9$ & $270.819 \pm 289.6842$ & \multirow{2}{*}{1.95} & 0.0583 \\
\hline Range & $15.139-2500$ & $25.507-923.059$ & & \\
\hline
\end{tabular}

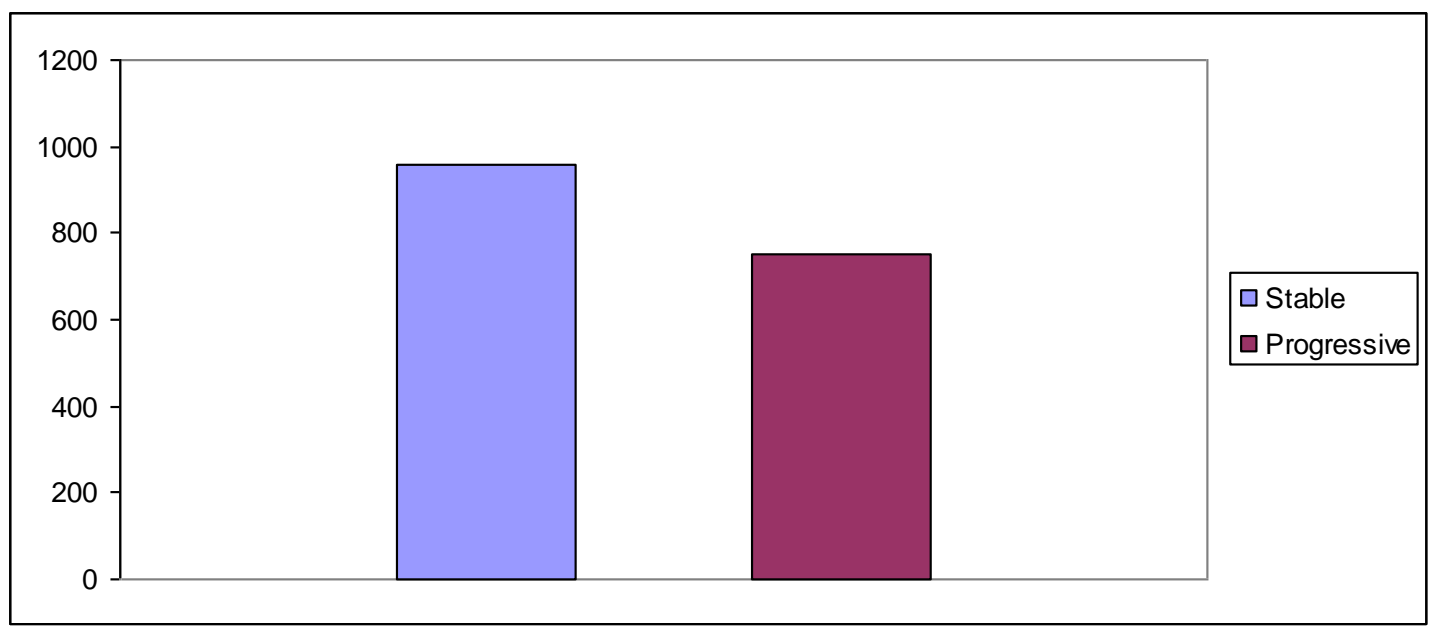


3. Comparison between level of IL-23 in patients according to disease type

\begin{tabular}{|c|c|c|l|l|}
\hline & Stable & Progressive & T-test & P-value \\
& $(\mathbf{1 1})$ & $\mathbf{( 2 9 )}$ & & \\
\hline Mean \pm SD & $958.955 \pm 1026.821$ & $749.62 \pm 958.96$ & \multirow{2}{*}{0.604} & \multirow{2}{*}{0.5488} \\
\hline Range & $20.689-2500$ & $15.139-2500$ & & \\
\hline
\end{tabular}

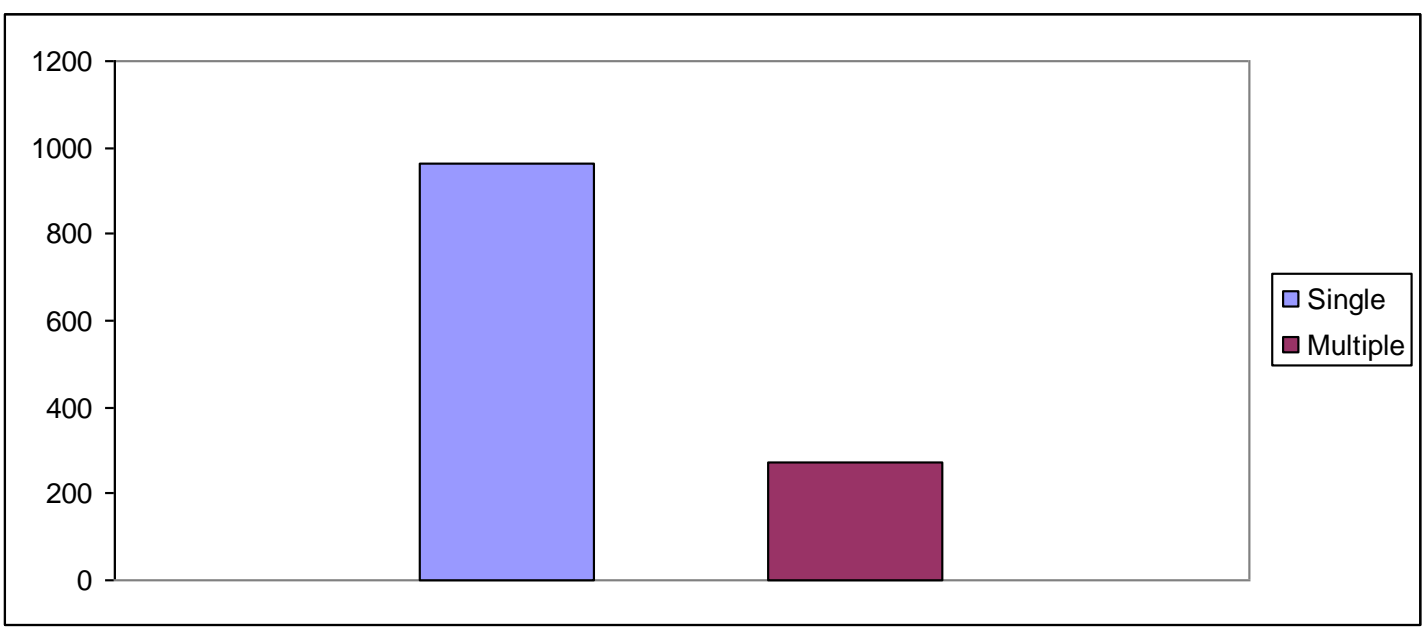




\section{DISCUSSION}

Alopecia areata is a common, chronic inflammatory disease characterized by nonscarring hair loss on the scalp or any hairbearing area of the body. Although the pathogenesis of AA has not been fully elucidated, clinical and experimental studies have shown that AA is a $\mathrm{T}$ cell-mediated autoimmune disease that targets the anagenstage hair follicles [4]. Furthermore, an alteration of the CD4+T cell subsets, including Th1, Th2, Th17 cells, and regulatory T cells, has been found in AA subjects [5].

There was a statistically significant difference between the 2 groups regarding level of IL-23 as IL-23 in group 1 was $807.19 \pm 969.293$ and in group 2 was $1359.8 \pm 1149$. This was in agreement with [6].

Another study found that immunohistochemistry of IL-23 showed positive cells in the intra-follicular epithelium and peribulbar dermis in affected hair follicles of pretreatment lesional scalp and very few cells in post-treatment AA scalp [7], raising stronger suggestion for IL-23 role in the AA disease pathogenesis [8].

\section{CONCLUSION}

Our study revealed higher serum level of IL23 in AA patient, so it may suggests it's role in AA pathogenesis.

\section{References}

\section{[1] Puwipirom H, Hirankarn N, Sodsai} P,Avihingsanon Y, Wongpiyabovorn J, Palaga T (2010): Increased interleukin-23 receptor $+\mathrm{T}$ cells in peripheral blood mononuclear cells of patients with systemic lupus erythematosus. Arthritis research \& therapy; 12(6): 215.
[2] Nalbandian A, Crispin JC and Tsokos

GC (2009): Interleukin-17 and systemic lupus erythematosus: current concepts. Clin Exp Immunol; 157:209-215.

\section{[3] Wong CK, Lit LC, Tam LS, Li EK,} Wong PT, Lam CW (2008): Hyperproduction of IL- 23 and IL-17 in patients with systemic lupus erythematosus: implications for Th17mediated inflammation in auto-immunity. Clin Immunol; 127:385-393.

[4] Ito T and Tokura Y (2014): The role of cytokines and chemokines in the T-cellmediated autoimmune process in alopecia areata. Exp Dermatol; 23:787-91.

\section{[5] Tembhre MK and Sharma VK (2013):}

$\mathrm{T}$-helper and regulatory $\mathrm{T}$-cell cytokines in the peripheral blood of patients with active alopecia areata. Br J Dermatol; 169:543-48.

[6] Bilgic O, Sivrikaya A, Unlu A, Altinyazar HC (2016): Serum cytokine and chemokine profiles in patients with alopecia areata. J Dermatolog Treat; 27(3):260-3.

\section{[7] Fuentes-Duculan J, Gulati N, Bonifacio} KM, Kunjravia N, Zheng X, SuárezFariñas M, Shemer A, Guttman-Yassky E, Krueger JG (2016): Biomarkers of alopecia areata disease activity and response to corticosteroid treatment. Exp Dermatol; 25(4):282-6.

[8] Renert-Yuval Y and Guttman-Yassky E (2016): A novel therapeutic paradigm for patients with extensive alopecia areata. Expert Opin Biol Ther; 16(8):1005- 